\title{
Artigos
}

\section{Pontos positivos e negativos observados em uma experiência prática com pares educativos em prevenção de aids numa escola secundária em São Paulo, Brasil}

\author{
Strengths and weakness observed on a practical \\ experience with peer educators for AIDS prevention in a \\ Secondary school in São Paulo, Brazil
}

\author{
Leila Strazza1', Eduardo Massad², Heráclito Barbosa de Carvalho³
}

\begin{abstract}
Strazza L, Massad E, Carvalho HB. Pontos positivos e negativos observados em uma experiência prática com pares educativos em prevenção de aids numa escola secundária de São Paulo, Brasil. Saúde, Ética \& Justiça. 2008;13(2):51-9.

Resumo: Pares educativos são uma importante ferramenta educativa utilizada internacionalmente com boas avaliações na eficácia. O presente estudo tem por objetivo avaliar o processo de implantação de pares educativos como programa de prevenção em uma escola modelo da periferia de São Paulo, com alunos de ensino médio, no período de 2003 a 2004. O trabalho foi aplicado em fases: identificação dos principais problemas frente à epidemia HIV/aids naquela escola, elaboração e aplicação de um questionário em 115 alunos e realização de quatro oficinas de sexo seguro. Na implantação desse processo foram destacados os principais pontos positivos e negativos. Como pontos positivos destacaram-se: elaboração do questionário, aceitação de materiais didáticos utilizados nas oficinas. Como pontos negativos destacaram-se: resistência da escola impondo limites no processo; obstrução na inserção do problema principal desta escola no questionário, indicação dos pares educativos e falta de tempo dos funcionários.
\end{abstract}

Descritores: Adolescentes. Ensino fundamental e médio. Síndrome da imunodeficiência adquirida/prevenção \& controle. Prevenção de doenças. Saúde escolar.

INTRODUÇÃO

$$
\text { A }
$$
partir da caracterização da pandemia de HIV/aids ${ }^{1}$, a única forma de intervenção conhecida limitava-se às campanhas de prevenção que tinham como estratégia transmitir o conhecimento acerca do vírus e suas formas de transmissão.

A idéia de desenvolver projetos de prevenção enfocando a educação tem sido usada como estratégia de controle entre a população jovem, que é bastante acometida pela epidemia de aids. Consequentemente, ocontexto escolaré privilegiado no desenvolvimento de ações preventivas por ser considerado o espaço de maior frequência de adolescentes e jovens ${ }^{2}$. Acredita-se na importância de se concentrarem intervenções preventivas na população acima citada para a possibilidade da

1 Pesquisadora Doutora, Disciplina de Informática Médica da Faculdade de Medicina da USP, LIM 01-FMUSP.

2 Professor Titular da Disciplina de Informática Médica e Chefe do Departamento de Medicina Legal, Ética Médica e Medicina Social e do Trabalho da Faculdade de Medicina da USP, LIM 01- HC-FMUSP.

3 Professor Doutor, Departamento de Medicina Preventiva da Faculdade de Medicina da USP, LIM 39-HC-FMUSP.

Endereço PARA CoRRESPondÊnCia: Leila Strazza. Instituto Oscar Freire, Faculdade de Medicina da USP. Rua Teodoro Sampaio, 115, São Paulo, SP. CEP 05405-00. E-mail: strazza@usp.br. 
Strazza L, et al. Pontos positivos e negativos observados em uma experiência prática com pares educativos em prevenção de aids numa escola secundária de São Paulo, Brasil.

adoção de novos comportamentos ${ }^{3}$.

Pesquisadores internacionais consideram que a abordagem de pares educativos tem sido bem aceita e vários estudos afirmam que, ao utilizar os pares educativos, isto é, os próprios jovens como agentes de educação torna-se mais fácil reconhecer e assimilar as informações de prevenção do HIV ${ }^{3-6}$.

No Brasil, embora os pares educativos sejam menos explorados, podemos apontar cinco estudos realizados com esse tipo de intervenção com bons resultados ${ }^{2,7-10}$.

Observou-se no estudo de Ayres ${ }^{7}$, dentro de uma escola, que, para os professores, o desinteresse dos alunos é uma das principais dificuldades do trabalho de prevenção. No entanto, quando foi realizada esta estratégia de desenvolvimento de educação em saúde pelos jovens, eles não só mostraram ampla aceitação como também obtiveram um real aproveitamento ${ }^{7}$.

Calazans $^{2}$ chama a atenção para artigos da literatura internacional, em sua maioria proveniente dos Estados Unidos, que mostram avaliações quantitativas e demonstram a boa eficácia deste programa, porém com poucos aspectos do processo. Ela ${ }^{2}$ aponta dois estudos, um internacional ${ }^{11}$ e outro nacional ${ }^{7}$, que tratam da experiência dos pares como educadores e observam a eficácia do programa, mas na ótica da comparação e da avaliação da efetividade do programa de prevenção.

Por outro lado, um fenômeno bastante comum observado e importante de se compreender é o fato de que as pessoas, em especial aqueles jovens que, criados participando de programas educativos sobre a transmissão do HIV, precisem ainda de educação sexual, pois acabam apresentando atitudes relutantes à aceitação desse processo ${ }^{12-16}$. Quais seriam as dificuldades da implantação de um programa com tanto potencial e que muitas vezes falha diante de obstáculos reais encontrados? Diante desse questionamento e do fato de que a técnica de pares educativos já ter sido aceita nacional ${ }^{11}$ e internacionalmente ${ }^{7}$ como uma es tratégia de prevenção, este estudo tem como objetivo apresentar os pontos positivos e negativos encontrados durante a implantação desta ferramenta numa escola brasileira, contribuindo na compreensão desse processo.

\section{MÉTodos}

Este estudo foi realizado em uma escola pública modelo da periferia da cidade de São Paulo, com alunos do terceiro ano do Ensino Médio matutino. Foi escolhido esse grupo por duas razões: a primeira por tratar-se de uma faixa de idade em que a maturidade sexual permitia a aplicação da ferramenta, e a segunda que a escola já tinha aula de educação sexual no seu currículo escolar para esta série.

O trabalho foi desenvolvido em diversas etapas. Primeiramente foi feito contato com a escola por meio das instâncias superiores. A direção desta escola aceitou a solicitação da Diretora de Ensino para a execução do trabalho, mas fez questão de indicar quem deveriam ser os pares educativos - professores e alunos, apesar de nossa sugestão contrária. Esses pares foram formados por oito alunos (quatro de cada sexo) e quatro professores (três professoras e um professor). O projeto foi desenvolvido em três fases:

1. identificação dos principais problemas da escola frente à epidemia HIV/aids, para serem incorporados a um questionário padrão - outubro e novembro de 2003;

2. aplicação do questionário para 115 alunos fevereiro de 2004;

3. execução de oficinas de sexo seguro - março a novembro de 2004.

Os professores participaram como coordenadores na execução das oficinas. Eles, juntamente com os alunos, participaram de reuniões mensais, nas quais foram treinados e supervisionados, separadamente, durante o decorrer do ano.

O questionário padrão acrescido das questões incorporadas na primeira fase foi aplicado na sala de aula, com uma única recusa. Os dados obtidos do questionário foram armazenados e analisados com a utilização do Epi-Info versão 6.0.

Oficinas de sexo seguro: foi trabalhada a questão de gênero ${ }^{17} \mathrm{com}$ os alunos divididos em quatro salas de aula (duas com meninas e duas com meninos).

As oficinas foram inspiradas em várias técnicas: na "pedagogia do oprimido" de Freire ${ }^{18}$, com proposta de educação dialógica; no trabalho de Pichon ${ }^{19}$, que utiliza técnicas de psicodrama e técnicas de educação/intervençãonasexperiênciasbrasileiras ${ }^{20}$. A principal idéia era que grupos educacionais deveriam analisar problemas e criar soluções. As oficinas terminavam com a demonstração do uso correto da camisinha.

Foram utilizados materiais didáticos escolhidos e já testados anteriormente para cada situação co- 
mo, por exemplo: o labirinto ${ }^{21}$, que é um recurso educativo na prevenção da aids considerado um material atraente, interativo, capaz de proporcionar ao indivíduo a percepção da sua própria vulnerabilidade ao HIV. Através dele, de forma simulada, o aluno pode envolver-se em situações de risco, e se estimula a reflexão para um posterior debate; histórias escritas, abordando temas propostos ${ }^{28}$; desenho da cara da aids, artifício lúdico no qual o aluno termina por representar suas fantasias e medos. Após a aplicação destes materiais, os alunos discutem em grupo o conteúdo dos mesmos. Segundo Rubin ${ }^{22}$ é nesta vivência de se falar em grupo que pessoas com problemas semelhantes interagem, quer seja perguntando, respondendo, ou mesmo somente ouvindo diferentes opiniões. Isso é importante porque os alunos, a princípio, tentam buscar uma solução para esses problemas. Caso não encontrem, pelo menos passam, a partir de então, a identificá-los, o que em última instância é o primeiro passo para uma solução; teatro espontâneo ${ }^{23}$ - segundo Marineau ${ }^{24}$, a dinâmica destes grupos cria a possibilidade das tensões sociais emergirem e se reduzirem conforme a maneira das pessoas integrarem estes grupos sociais artificiais.

O material - histórias e desenhos - destas oficinas era colocado em urnas lacradas no dia em que elas ocorriam e entregues aos professores que coordenavam o projeto e posteriormente à pesquisadora principal do projeto, durante as supervisões. Os resultados foram relatados à pesquisadora acima citada pelos pares educativos, também nas supervisões mensais, com anotações de seus conteúdos. Em cada encontro com os pares educativos sempre foram respeitadas as sugestões da reunião anterior, porém, os mesmos tinham pouco a acrescentar, pois tinham uma preocupação constante de continuarem a ser aceitos pelos colegas. Cada oficina teve duração de cem minutos e elas foram realizadas nas aulas de aconselhamento sexual. Contamos com uma média de 25 alunos por sala de aula.

No primeiro semestre, a pedido dos alunos, os pares educativos foram formados por quatro professores - três professoras e um professor -, e oito alunos (quatro de cada sexo). Na primeira e na segunda oficina de um total de oito, os professores conduziram os trabalhos, sendo que as demais foram conduzidas pelos pares educativos formados por alunos (dois em cada sala).
No final do semestre foi avaliada a preferência dos alunos quanto à realização das oficinas de sexo seguro $^{25}$, isto é, sobre quem deveria continuar a dar as mesmas no segundo semestre. A preferência foi dada aos pares educativos formados por alunos. Aos professores coube somente a tarefa de coordenação das oficinas.

As supervisões foram dadas aos professores no horário de almoço e, aos pares educativos, na última aula do dia, sendo que os professores, nestas aulas, colaboraram ao registrar presença a estes alunos.

Aspectos éticos: $O$ protocolo $n^{\circ} 1041 / 03$ de pesquisa foi aprovado pela Comissão de ÉticaCAPPesq HCFMUSP.

\section{Resultados}

Os resultados serão apresentados conforme as fases de execução.

Primeira fase - Um resumo dos problemas identificados com os professores e com os alunos são apresentados nas Tabelas 1 e 2 respectivamente.

Por meio das reuniões com os pares educativos - professores e alunos - foi apresentado um diagnóstico (Tabelas 1 e 2). Baseadas nesse diagnóstico foram propostas estratégias e diretrizes para um programa educativo que teve duas partes, respectivamente, a utilização de um questionário auto-aplicativo de múltipla escolha com questões fechadas abordando comportamento e hábitos dos alunos do projeto, com a finalidade de ajudar os pares educativos na informação e a realização das quatro oficinas de sexo seguro.

Segunda Fase - Análise do Questionário - O questionário foi aplicado para 115 alunos de terceiro ano do Ensino Médio matutino, com uma recusa. $54 \%$ (72) alunos e $46 \%$ (42) alunas, com idade média de 16,7 anos. Um aluno era casado, os restantes solteiros. Com relação às perguntas: Você sabe como a aids se transmite? Sim 86\% (98); Não 2,6\% (3) e tem dúvidas 12\% (14); Qual seu risco de pegar aids? Nenhum $41 \%$ (42); pequeno $38 \%$ (39); moderado 13\% (13) e alto risco 9\% (9).

Com relação ao tipo de parceria sexual: parceiros regulares 52\% (27); casual 23\% (12) e ambos 25\% (13). $45 \%$ dos (as) alunos (52) referiram ter feito sexo com penetração.

Um resumo sobre a questão que abordava o tema: conversar sobre sexo é apresentado na Tabela 3.

Quanto ao uso de drogas: $34 \%$ (39) dos alunos 
Strazza L, et al. Pontos positivos e negativos observados em uma experiência prática com pares educativos em prevenção de aids numa escola secundária de São Paulo, Brasil.

responderam nunca ter usado álcool e 46\% (69) nunca terem usado droga ilícita. Somente um aluno referiu ter feito uso de droga injetável. Onze por cento (13) referiram ter feito sexo com alguém que já tivesse feito uso de drogas, sendo que $74 \%$ (33) não e 15\% (11) não sabiam.

Postura diante de palestras sobre aids na escola: $69 \%$ (78) dos alunos responderam que acompanhavam com atenção e ninguém se manifestou dizendo ser um assunto chato.

Perguntados sobre "ter ficado", isto é, relacionamento por curto período de tempo, com alguém com aids alguma vez, $85 \%$ (95) dos alunos disse que não e 15\% (17) não sabiam. Porém, quando perguntamos se já haviam feito sexo com alguém que sabidamente tivesse aids, obtivemos uma resposta positiva.

Terceira Fase - Oficinas de Sexo Seguro - Foram realizadas oito oficinas em 2004. Quanto à preferência pelo melhor "par educativo", a distribuição foi: $62 \%$ (71) o aluno; $17 \%$ (19) o professor; $22 \%$ (25) em branco. Solicitou-se a explicação da escolha, e assim tivemos: "Os professores explicam muito bem, mas eu vou ficar com os alunos porque eu acho que com eles a gente tem mais liberdade... Eles falam a nossa linguagem".

Porém, o principal problema encontrado nesta escola, ou seja, a gravidez, não foi abordado no questionário, pois segundo os professores que estavam na coordenação, este assunto não deveria ser destacado, pois os alunos poderiam sentir-se constrangidos. Os professores acreditavam que este assunto seria abordado pelos alunos naturalmente durante as oficinas de sexo seguro. Contrariando essa premissa, a gravidez não foi relatada pelos alunos em nenhum momento das oficinas.

Outros dois importantes tópicos abordados no questionário, um referente à dificuldade de conversar com os pais sobre sexualidade, e outro sobre drogas, não foram discutidos pelos alunos em nenhuma oficina. Atenta a estes tópicos, a equipe do projeto solicitou e insistiu com a direção da escola para que se realizasse uma reunião com esses pais. A direção, no entanto, sempre se a propôs agendála num momento oportuno que não se concretizou.

Na primeira e na segunda oficina de sexo seguro, dadas pelos professores, segundo seus relatos, os alunos demonstraram amplo conhecimento sobre HIV e aids, o que não os surpreendeu, devido aos inúmeros projetos e campanhas sobre o tema naquela escola, desde 1997.
A terceira e quarta oficinas foram dadas pelos pares educativos formados por alunos. Eles solicitaram aos colegas que desenhassem individualmente "A cara da aids" e escrevessem uma história - Como o jovem sente a aids?

Os desenhos apresentados foram caveiras, caixões de defunto, entre outros. Selecionaram um desenho e discutiram em grupo. Nestas discussões surgiu primeiramente a visão da aids como doença fatal e posteriormente como doença crônica fatal, mas controlável por medicação e que o doente é passível de boa qualidade de vida, tanto física como emocional.

A quinta oficina teve como tema a figura de um labirinto $^{21}$ com a seguinte pergunta: Quem pode transmitir aids?

As histórias foram escritas individualmente. Os grupos selecionaram uma história em cada classe. Foi sugerido, então, o psicodrama, um teatro espontâneo baseado em Moreno ${ }^{23}$, como forma de apresentação. As meninas acolheram a idéia e os meninos solicitaram a discussão em grupo.

A sexta oficina teve como tema: A negociação da camisinha. Foi solicitada uma história escrita individualmente, que foi posteriormente selecionada discutida pelos meninos e dramatizada pelas meninas.

Acrescentamos que o sucesso do teatro espontâneo foi tão grande nas classes femininas que elas pediram que esta forma de oficina de sexo seguro fosse repetida sempre.

Nas histórias escritas ficou muito clara a questão de gênero ${ }^{17}$, em que prevaleceu a acusação mútua, que teve como conseqüência um amplo debate, no qual as meninas disseram que se sentiam obrigadas a submeter-se ao seu parceiro que não gosta de usar camisinha, mas sai por aí "catando" qualquer uma pra mostrar que é macho. Segundo os meninos, as meninas estão muito "atiradas" e é só esse homem ter moto e carro, elas já "caem em cima dele".

$\mathrm{Na}$ sétima oficina, mesmo não fazendo parte do desenho inicial do projeto, foi atendido o pedido dos alunos de criar a possibilidade de misturar meninos com meninas em pares para conversarem sobre aids e escreverem uma história sobre: Qual seria sua atitude se um(a) namorado(a) Ihe revelasse ser HIV+?

Eles solicitaram não ler as histórias em voz alta e somente depositá-las nas urnas. Das cinqüenta histórias escritas, quarenta e duas revelavam que continuariam amigos da pessoa, sete não iriam querer mais vê-la(lo), pois teriam "medo". Chamou 
a atenção uma última história que dizia: "esta é uma história verdadeira", abordando o receio e angústia de contar para o parceiro que era HIV+ desde o nascimento e a decisão de não falar a verdade.

$\mathrm{Na}$ oitava oficina pedimos a todos os alunos presentes que avaliassem aquela forma de trabalho daquele ano e entre agradecimentos, elogios, recebemos mensagens que diziam: "...que saco: aids, aids, aids, saí dessa!... Não agüento mais falar de aids..."

Durante as supervisões percebeu-se que os pares educativos acrescentavam muito pouco, além disso tinham uma preocupação constante em serem aceitos pelos colegas. $O$ fato de terem sido escolhidos pela direção da escola, que utilizou os critérios - melhores notas no currículo escolar e no comportamento - deixou-os inseguros quanto ao papel que desempenhavam. Acrescentando-se a isso fato de os alunos contestarem freqüentemente não terem sido consultados na escolha dos pares educativos, pois, segundo eles, poderiam indicar pessoas mais adequadas para desempenhar esse papel.

Em dezembro de 2004 apresentamos os resultados do programa educativo à escola que, neste dia, nos ofereceu uma festa de encerramento do projeto, porém não nos convidou a permanecer em 2005.

\section{Dıscussão}

Apesar de a literatura internacional citar "pares educativos" como um método pedagógico de longa história, datado da década de $80^{4,5,6}$, vivenciamos sua aplicação e identificamos os pontos positivos e negativos desta experiência:

Pontos Positivos: A elaboração do questionário serviu tanto para identificar os problemas da escola e dos alunos, como também para dar segurança aos pares educativos na realização de seu trabalho. A falta de comunicação com os pais é um exemplo de informação que deve ser ressaltado.

Os materiais didáticos como o labirinto e as histórias escritas foram muito bem aceitos pelos participantes. Quanto ao teatro espontâneo, o que se observou foi uma boa aceitação por parte das meninas, o que não aconteceu com os meninos que se sentiram constrangidos e pediram para discutir em grupo, em substituição. Mesmo não fazendo parte do desenho inicial do projeto, atender sempre às solicitações de ajuste dos participantes criou a possibilidade de misturar meninos com meninas em pares para conversarem sobre aids.

Fazer demonstração do uso correto da camisinha no final de todas as oficinas de sexo seguro, além de ser educativo, acabou causando descontração no final daquele dia de reflexão, contribuindo para melhorar a integração do grupo.

Pontos Negativos: Limites de ação impostos pela escola ao projeto e aceitos por receio de não se executar o estudo. Por exemplo, a gravidez que foi levantada, tanto pelos alunos como pelos professores, como problema central daquela escola não pôde ser colocada em forma de pergunta no questionário, que é um instrumento poderosíssimo de intervenção, pois, além de sensibilizar e esquentar o grupo, leva à reflexão sobre o que cada um fez e faz ${ }^{17}$ e, assim sendo, favorece a busca de uma solução entre os próprios alunos. Os professores alegaram que os alunos poderiam sentir-se constrangidos com essa forma de abordagem do tema e, que de forma natural, este tema apareceria nas oficinas de sexo seguro - o que não aconteceu durante todo o ano; o fato dos pares educativos serem escolhidos pela escola acaba gerando a falta de interatividade entre eles. Reuniões com os pais dos alunos devem ser colocadas desde 0 início, eles devem ser alertados e ajudados quanto à educação sexual de seus filhos.

Nenhuma atividade prática deve ser dada sem que a mesma tenha um retorno. Ou seja, quando alguns alunos enviaram mensagens de insatisfação, o "staff" ficou sem saber o porquê de tal comportamento no final de um ano de total participação.

Pontos de Semelhança: Quanto às dificuldades enfrentadas em outros estudos, observou-se que a escolha dos pares educativos ser feita pela escola gera falta de interatividade entre eles ${ }^{26}$; a falta de tempo alegada pela escola 7 .

Apesar de termos certeza de que poderíamos ter feito mais neste projeto, ficou claro para nós que, embora fôssemos insistentes em alguns momentos, trabalhamos com o que nos foi permitido pela escola e que, errados ou certos nesta aceitação, procuramos tirar lições desta experiência.

Limites do estudo: Vários são os pontos que podem ser levantados neste item, como, por exemplo, trabalhar-se somente com uma determinada série, ou com uma determinada escola. O último caso pode interferir de maneiras distintas no relacionamento com os executores da intervenção, o que de certa 
Strazza L, et al. Pontos positivos e negativos observados em uma experiência prática com pares educativos em prevenção de aids numa escola secundária de São Paulo, Brasil.

forma interfere nos resultados finais.

\section{Considerações Finais}

Mesmo conscientes de que as limitações metodológicas impostas durante a execução do projeto pela escola podem ter tido influência nos resultados obtidos, concordamos com Paiva ${ }^{25}$ ao afirmar que a educação entre pares rompe com a estratégia de prevenção tradicional em HIV/aids e estimula práticas educativas entre agentes e usuários com compartilhamento de linguagens, experiências pessoais e sociais.
Este estudo mostrou que esta metodologia de pares educativos, comprovadamente aceita no exterior, é uma estratégia que deve ser explorada também no Brasil com profissionais de saúde e diretores de escolas, sendo que o mais importante é querer assumir com responsabilidade um verdadeiro programa educativo para a mudança do comportamento de risco. Ao apontar esta estratégia de pares educativos para escolas, não podemos deixar de lembrar que a escola, além de ter papel importante na formação de cidadania do jovem, não pode omitir-se na construção de novos valores.

Tabela 1 - Resumo dos problemas identificados pelos professores de alunos do terceiro ano do ensino médio matutino, de escola pública da periferia de São Paulo no final de 2003 e no ano de 2004

\begin{tabular}{|c|c|c|c|c|c|}
\hline $\begin{array}{l}\text { Participação } \\
\text { dos professores }\end{array}$ & Sexo & $\begin{array}{l}\text { Maior problema } \\
\text { de vulnerabili- } \\
\text { dade naquela } \\
\text { escola }\end{array}$ & Drogas & Família & $\begin{array}{l}\text { Conclusão dos professo- } \\
\text { res sobre projetos HIV/aids }\end{array}$ \\
\hline $\begin{array}{l}\text { "Confesso que } \\
\text { tenho falta de } \\
\text { conhecimento } \\
\text { sobre HIV/ } \\
\text { AIDS... medo de } \\
\text { passar informa- } \\
\text { ção errada". }\end{array}$ & $\begin{array}{l}\text { "Os(as) } \\
\text { alunos(as) per- } \\
\text { guntam muito so- } \\
\text { bre tudo que diz } \\
\text { respeito à saúde. } \\
\text { Eu recorto tudo } \\
\text { sobre saúde". }\end{array}$ & GRAVIDEZ & $\begin{array}{l}\text { "Tenho a } \\
\text { impres- } \\
\text { são que } \\
\text { não está } \\
\text { tão forte. } \\
\text { Há dois } \\
\text { anos } \\
\text { atrás, no } \\
\text { curso da } \\
\text { manhã, } \\
\text { teve alu- } \\
\text { nos que } \\
\text { vieram } \\
\text { droga- } \\
\text { dos". }\end{array}$ & $\begin{array}{l}\text { "A maioria } \\
\text { vem nas } \\
\text { reuniões". }\end{array}$ & $\begin{array}{l}\text { "Todos os anos tem projeto } \\
\text { sobre aids...tudo começou } \\
\text { em 1997, nesta escola. } \\
\text { É bater na mesma tecla e } \\
\text { não resolver nada e tem } \\
\text { mais, sempre com a mesma } \\
\text { informação: sexo, drogas... } \\
\text { é um assunto desgastante... } \\
\text { elaborou-se um questionário } \\
\text { e os(as) alunos(as) res- } \\
\text { ponderam, foi até feito um } \\
\text { banco de dados, mas não } \\
\text { teve resposta nenhuma...foi } \\
\text { um trabalho lindo, mas sem } \\
\text { conclusão?”. }\end{array}$ \\
\hline $\begin{array}{l}\text { "Eu tenho dúvida } \\
\text { sobre isso. } \\
\text { Nunca me permiti } \\
\text { falar sobre isso, } \\
\text { vou me por a } \\
\text { prova." }\end{array}$ & "é difícil!" & $\begin{array}{l}\text { "tanto menino } \\
\text { quanto menina } \\
\text { chegam desespe- } \\
\text { rados... a gente } \\
\text { manda para o } \\
\text { Posto de Saúde } \\
\text { para uma melhor } \\
\text { orientação." } \\
\text { "Elas não tem ver- } \\
\text { gonha de dizerem } \\
\text { que estão } \\
\text { grávidas" }\end{array}$ & & $\begin{array}{l}\text { "eles } \\
\text { gostam } \\
\text { de ouvir e } \\
\text { falar" }\end{array}$ & \\
\hline $\begin{array}{l}\text { "O assunto é } \\
\text { importante, } \\
\text { vulnerabilidade é } \\
70 \% \text { do assunto } \\
\text { principal dos } \\
\text { concursos". }\end{array}$ & $\begin{array}{l}\text { "eles(as) rece- } \\
\text { bem bem o tra- } \\
\text { balho da aids e } \\
\text { encaram o sexo } \\
\text { numa boa....fico } \\
\text { chocada, sem } \\
\text { ação!" }\end{array}$ & & & $\begin{array}{l}\text { "os pais } \\
\text { vem à reu- } \\
\text { nião, se } \\
\text { a religião } \\
\text { deixar... } \\
\text { é decisivo } \\
\text { para eles". }\end{array}$ & \\
\hline
\end{tabular}


Strazza L, et al. Pontos positivos e negativos observados em uma experiência prática com pares educativos em prevenção de aids numa escola secundária de São Paulo, Brasil.

Tabela 2 - Resumo dos problemas identificados pelos alunos do terceiro ano do ensino médio matutino, de escola pública da periferia de São Paulo no final de 2003 e no ano de 2004

\begin{tabular}{|c|c|c|c|c|c|}
\hline $\begin{array}{l}\text { Participação } \\
\text { dos alunos } \\
\text { em projetos } \\
\text { HIV/aids }\end{array}$ & Sexo & $\begin{array}{l}\text { Maior proble- } \\
\text { ma de } \\
\text { vulnerabilda- } \\
\text { de naquela } \\
\text { escola }\end{array}$ & Drogas & Família & $\begin{array}{l}\text { Conclusão } \\
\text { dos alunos } \\
\text { sobre } \\
\text { projetos } \\
\text { HIV/aids }\end{array}$ \\
\hline \multirow[t]{3}{*}{$\begin{array}{l}\text { "a participação é } \\
\text { bem grande." } \\
\text { "quem sabe este } \\
\text { projeto vai dar } \\
\text { certo..." }\end{array}$} & $\begin{array}{l}\text { "falar de sexo } \\
\text { todo mundo } \\
\text { gosta, mas usar } \\
\text { camisinha... } \\
\text { ninguém usa } \\
\text { e "pimba" Dá } \\
\text { gravidez!" }\end{array}$ & GRAVIDEZ & $\begin{array}{l}- \text { "As } \\
\text { drogas } \\
\text { diminuíram } \\
\text { muito...a } \\
\text { gravidez é } \\
\text { o assunto } \\
\text { do mo- } \\
\text { mento." }\end{array}$ & $\begin{array}{l}\text {-"a questão social é boa } \\
\text { dentro da escola. Antes } \\
\text { os pais achavam que eles } \\
\text { teriam que falar e, agora há } \\
\text { uma integração de esco- } \\
\text { la/casa e eles se sentem } \\
\text { mais soltos para falar com } \\
\text { todos,mas...repito: na } \\
\text { escola!. Em casa não se } \\
\text { questiona." }\end{array}$ & $\begin{array}{l}\text { "Tem } \\
\text { espaço pra } \\
\text { projeto, mas } \\
\text { não tem } \\
\text { espaço para } \\
\text { os alunos } \\
\text { falarem" }\end{array}$ \\
\hline & \begin{tabular}{l|} 
"sexo é'uma \\
coisa normal. \\
Não sei porque \\
alguém vê como \\
um bicho de sete \\
cabeças".
\end{tabular} & $\begin{array}{l}\text { "Tem bastante } \\
\text { informação... } \\
\text { sabe-se que } \\
\text { tem que usar } \\
\text { camisinha, mas } \\
\text { ninguém usa". }\end{array}$ & & $\begin{array}{l}\text { "Não me sinto à vontade em } \\
\text { conversar com a minha mãe } \\
\text { sobre sexo. Não gosto de } \\
\text { ficar em casa, ela vem com } \\
\text { umas perguntinhas que me } \\
\text { incomodam". }\end{array}$ & $\begin{array}{l}\text { "Os profes- } \\
\text { sores não } \\
\text { se sentem } \\
\text { à vontade } \\
\text { para falar } \\
\text { sobre sexo, } \\
\text { parece que } \\
\text { eles têm } \\
\text { vergonha". }\end{array}$ \\
\hline & & & & $\begin{array}{l}\text { "Eu não consigo falar de } \\
\text { sexo em casa, é um tabú, } \\
\text { quando vem uma mulher } \\
\text { pelada na televisão, minha } \\
\text { mãe muda de canal". }\end{array}$ & $\begin{array}{l}\text { "tem muito } \\
\text { projeto, mas } \\
\text { só dá infor- } \\
\text { mação...a } \\
\text { gente não } \\
\text { pode falar!". }\end{array}$ \\
\hline
\end{tabular}

Tabela 3 - Questões apresentadas para os alunos do terceiro ano do ensino médio matutino, de escola pública, da periferia de São Paulo, no final de 2003 e no ano de 2004, abordando tipos de pessoas com quem conversam sobre sexo

\begin{tabular}{l|c|c}
\hline Questão & Sim (\%) & Não (\%) \\
\hline Você conversa sobre sexo com seu pai? & $13(11)$ & $102(89)$ \\
Você conversa sobre sexo com sua mãe? & $55(48)$ & $60(52)$ \\
Você conversa sobre sexo com seus (suas) amigos(as)? & $105(91)$ & $10(09)$ \\
Você conversa sobre sexo com seu (sua) parceiro(a)? & $64(56)$ & $51(44)$ \\
\hline
\end{tabular}

Strazza L, Massad E, Carvalho HB. Positive and negative spots observed on a practical experience with peer educators for AIDS prevention in a secondary school in São Paulo, Brazil. Saúde, Ética \& Justiça. 2008;13(2):51-9.

АвsтRAct: Peer education is an important educational tool used internationally presenting good ratings of its effectiveness. This article aims to understand the implementation process of Peer Education as a Brazilian's Prevention Program rolled in a model periphery São Paulo's school among its students during 2003 and 2004. This study was enrolled into phases: Identification of the main problems facing the school to the epidemic HIV / AIDS, to elaborate and apply a questionnaire on 115 students, and implementation of workshops on safe sex. They were then highlighted the strengths and weakness of the process. As strengths highlighted are: development of the supplement to the questionnaire, acceptance of the materials used in workshops and routines adopted with emphasis on the use of condoms. As weakness highlighted are: resistance from school imposing limits in the process, obstruction in the inclusion of questions in the questionnaire, indication of peer education and lack of time for their staff.

KEYwORDS: Peer education. HIV. School health. Education, primary and secondary. Adolescent. Acquired immunodeficiency syndrome/prevention \& control. Disease prevention. 
Strazza L, et al. Pontos positivos e negativos observados em uma experiência prática com pares educativos em prevenção de aids numa escola secundária de São Paulo, Brasil.

Agradecimentos: Este projeto foi financiado pelo Prof. Dr. Eduardo Massad - Titular da Informática Médica e Chefe do Departamento de Medicina Legal, Ética Médica, Medicina Social e do Trabalho da FMUSP - LIM 01 HC-FMUSP que sempre apóia novas estratégias de prevenção ao HIV/aids.

\section{REFERÊNCIAS}

1. Evans AS. Viral infections of humans, epidemiology and control. 3rd ed. New York: Plenum Medical Book; 1989.

2. Calazans G, et al. Plantões jovens: acolhimento e cuidado por meio da educação entre pares para adolescentes e jovens nos Centros de Testagem e Aconselhamento - CTA. Saúde Sociedade. 2006;15(1):22-36.

3. Maas FV, Otte WM. Evaluation of HIV/AIDS secondary school peer education in rural Nigeria, Health Education Research Advance Access published online on November 5, 2008. Health Education Research, doi:10.1093/her/cyn056.

4. Visser MJ. HIV/AIDS prevention through peer education and support in secondary schools in South Africa. Sahara J. 2007;4(3):678-94.

5. Campbell S. Using peer education projects to prevent HIV/AIDS in young people. Art Sci Sexual Health, Nursing Standard. 2005; Nurs Stand;20(10):50-5, 2005 Nov 16-22.

6. Helgerson SD, Peterson LR. Acquired immunodeficiency syndrome and secondary school students: their knowledge is limited and their want to learn more. Pediatrics. 1988;81:350-5.

7. Ayres JRCM, Freitas AC, Santos MAS, Saletti FHC, França Jl. Adolescência e aids: avaliação de uma experiência de educação preventiva entre pares. Interface - Comunic Saúde Educ (São Paulo). 2003;7(12):123-38.

8. Falavigna DLM, Falavigna G, Araújo SMDE, Pupulim ART, Dias MLGG, Marcondes NR. Formação de agentes multiplicadores em doenças parasitárias. Rev Bras Anal Clin. 2000;32(1):53-5.

9. Ribeiro FMT. A gestão em parceria de projetos de saúde em DST/AIDS: a emergência de um estilo gerencial: uma experiência testada [tese]. Rio de Janeiro: Universidade do Estado do Rio de Janeiro, Instituto de Medicina Social; 2000.

10. Brasil. Ministério da Saúde. Secretária de Políticas de Saúde. Coordenação Nacional de DST e AIDS. Manual do multiplicador - adolescente. Brasília; 2000.

11. Ebreo A, Price SF, Siewe Y, Zimmerman RS. Effects of peer education on the peer educators in a schoolbased HIV prevention program: where should peer education research go from here? Health Educ Behav. 2002;29(4):411-23.

12. Strazza L, Azevedo R, Carvalho H, Goto F, Burattini M, Massad E. Comparison of sexual behavior and drug use between adolescents from a private and a public school in a Sao Paulo, Brazil. In: XIII International AIDS Conference, Durban - South Africa, 9-14 July, 2000. Abstracts. Durban, South Africa; 2000. v.1, abstract TuPpD 1197.

13. Strazza L, Azevedo R, Carvalho HB, Massad E. Comparação do comportamento sexual, DST/AIDS e drogas entre adolescentes de uma escola particular e uma pública em São Paulo, Brasil. J Bras Doenças Sex Trans. 2003;15(3):21-3.

14. Ygao Y, Lu ZZ, Shi R, Sun XY, Cai Y. AIDS and sex education for young people in China. Reprod Fertil Dev (Austrália). 2001;13:729-37.

15. Nascimento LCSDO, Lopes CM. Atividade sexual e doenças sexualmente transmissíveis em escolares do $2^{\circ}$ grau de Rio Branco - Acre, Brasil. Rev Latinoam Enf (Ribeirão Preto). 2000;8(1):107-13.

16. Ravi KV, Sureender S, Guruswamy M. What do school children and teachers in rural maharashtra think of AIDS and sex? Health Transition Rev (Australia). 1997;7(Suppl):481-6.

17. Paiva V. Sexualidade e gênero num trabalho com adolescentes para prevenção do HIV/AIDS in a AIDS no Brasil. Rio de Janeiro: Relume - Dumará; 1994.

18. Freire P. Pedagogia do oprimido. Rio de Janeiro: Paz e Terra; 1970.

19. Pichon-Rivière E. The group process. São Paulo: Martins Fontes; 1988.

20. Fritzen SJ. Exercícios práticos de dinâmica de grupo. 33a ed. Petrópolis: Vozes; 2002. v.1, 2. 
Strazza L, et al. Pontos positivos e negativos observados em uma experiência prática com pares educativos em prevenção de aids numa escola secundária de São Paulo, Brasil.

21. NISM - Núcleo de Investigação de Saúde da Mulher. Casa da Mulher do Grajaú. Prancha VII, manual do vídeo "Seguro morreu de Velho". São Paulo; 1992.

22. Rubin HJ, Rubin IS. Qualitative interview: the art of hearing data. Estados Unidos, Sage: Thousand Oaks; 1995.

23. Moreno JL. Psicodrama. 16a ed. São Paulo: Cultrix; 1987.

24. Marineau RF. Jacob Levy Moreno 1889-1974: pai do psicodrama, da sociometria e da psicoterapia de grupo. São Paulo: Editora Agora; 1992.

25. Paiva V. Sem mágicas soluções: a prevenção e o cuidado em HIV/AIDS e o processo de emancipação psicossocial. Interface - Comunic Saúde Educ. 2002;6(11):25-38.

26. Koula M, Jenny KK. Peer education in HIV prevention: an evaluation in schools. Eur $\mathrm{J}$ Public Health. 2006;16(2):128-32.

Artigo recebido em 12/07/2008. Aprovado em 22/09/2008. 